OP0201 INCREASED RISK OF DEMENTIA IN PATIENTS WITH SYSTEMIC LUPUS ERYTHEMATOSUS

J. Lee ${ }^{1}$, Y. Eun ${ }^{1}$, I.Y. Kim², K. D. Han ${ }^{3}$, D. H. Kim ${ }^{3}$, S. Y. Kang ${ }^{1}$, S. Lee ${ }^{1}$, H. S. Cha ${ }^{1}$, E. M. Koh ${ }^{1}$, H. Kim ${ }^{1} .{ }^{1}$ Samsung Medical Center, Sungkyunkwan University School of Medicine, Department of Medicine, Seoul, Korea, Rep. of (South Korea); ${ }^{2}$ National Police Hospital, Department of Medicine, Seoul, Korea, Rep. of (South Korea); ${ }^{3}$ College of Medicine, The Catholic University of Korea, Department of Biostatistics, Seoul, Korea, Rep. of (South Korea)

Background: Systemic lupus erythematosus (SLE) is a chronic inflammatory disease that can affect any organ of the body. Nervous system involvement of SLE lead to a variety of neurologic and psychiatric manifestations, which are called neuropsychiatric lupus. Cognitive dysfunction may appear as part of neuropsychiatric lupus. There are several papers on the increase in dementia risk in SLE patients, but data are not sufficient and there is little data on whether SLE affects dementia differently depending on the dementia subtype.

Objectives: We evaluate dementia incidence and risk in SLE patients in a nationwide population-based cohort and determine whether the risk is different for each dementia subtype.

Methods: We identified patients aged 40 years or more, with systemic lupus erythematosus between 2008 and 2014 using the database of the National Health Insurance Service (NHIS) of south Korea. Patients who had previously been diagnosed with dementia were excluded from the study. A total of 11,288 SLE patients and 56,440 control subjects with a 1:5 age- and sex-matching were included in the study. The primary outcome of the study was incident dementia, which was defined by an ICD-10 code and the use of dementia medications. Kaplan-Meier curves and Cox proportional hazards regression analysis were used for the analysis.

Results: The incidence rate of dementia was higher in SLE cohort (3.90 per 1,000 person-years) than control cohort (2.73 per 1,000 person-years). Incidence rates of Alzheimer disease and vascular dementia were also higher in SLE cohort than control. SLE patients had a higher risk of dementia compared to control cohorts without SLE (crude hazard ratio $1.43,95 \% \mathrm{Cl} 1.25-1.63$ ). In patients with SLE, the risk of Alzheimer's disease was 1.4 times higher and the risk of vascular dementia 1.6 times higher than non-SLE control.

Conclusion: In this nationwide population-based cohort study, SLE patients had a 1.4-fold higher risk of incident dementia compared to patients without SLE. Further studies are warranted to identify mechanisms of increased risk of dementia in SLE patients. Monitoring of dementia incidence in SLE patients is needed in clinical practice.

Disclosure of Interests: None declared

DOI: 10.1136/annrheumdis-2020-eular.5280

\section{OP0202 STRESS-ACTIVATED MIR-204 GOVERNS SENESCENT PHENOTYPES OF CHONDROCYTES TO PROMOTE OSTEOARTHRITIS DEVELOPMENT}

Y. Cho ${ }^{1}$, D. Kang ${ }^{1}$, J. H. Kim ${ }^{1} .{ }^{1}$ Seoul National University, Seoul, Korea, Rep. of (South Korea)

Background: A progressive loss of cartilage matrix leads to the development of osteoarthritis (OA). Matrix homeostasis is disturbed in OA cartilage as the result of reduced production of cartilage-specific matrix and increased secretion of catabolic mediators by chondrocytes. Chondrocyte senescence is a crucial cellular event contributing to such imbalance in matrix metabolism during $\mathrm{OA}$ development.

Objectives: We sought to identify a previously unknown, senescence-associated signaling pathway in chondrocytes linked to major OA cartilage manifestations such as PG loss and cartilage degeneration.

Methods: We particularly aimed to screen miRNAs whose inhibition could effectively modulate senescent phenotypes of chondrocytes to treat OA. We investigated the regulatory mechanisms of miR-204 under various stress-eliciting stimuli in primary cultured human and mouse chondrocytes. We examined the in vivo effects of miR-204 overexpression and its antagonism in surgically induced OA mouse models. DMM surgery was used to induce posttraumatic OA in 12-week-old mice. Small RNAs were delivered to mouse knee joints by intra-articular injection. Various OA manifestations including cartilage destruction, subchondral bone sclerosis, osteophyte maturity, and synovial inflammation in mice were histologically inspected.

Results: We identify miR-204 as a senescence-associated microRNA (miRNA) which is markedly upregulated in OA cartilage. The upregulated miR-204 simultaneously targets multiple components of the sulfated proteoglycan (PG) biosynthesis pathway, effectively shutting down PG anabolism. Ectopic expression of the miR-204 in joints triggers spontaneous cartilage loss and OA development, whereas inhibition of miR-204 ameliorates experimental OA, with concomitant recovery of PG synthesis and suppression of inflammatory senescence-associated secretory phenotype (SASP) factors in cartilage

Conclusion: we unravel a stress-activated senescence pathway that underlies disrupted matrix homeostasis in OA cartilage.

References:

[1] O. H. Jeon, C. Kim, R.-M. Laberge, M. Demaria, S. Rathod, A. P. Vasserot J. W. Chung, D. H. Kim, Y. Poon, N. David, D. J. Baker, J. M. van Deursen, J. Campisi, J. H. Elisseeff, Local clearance of senescent cells attenuates the development of post-traumatic osteoarthritis and creates a pro-regenerative environment. Nat. Med. 23, 775-781 (2017)

Disclosure of Interests: None declared

DOI: 10.1136/annrheumdis-2020-eular.5295

\section{OP0203-HPR EVALUATION OF A 10-WEEK PROGRESSIVE RESISTANCE TRAINING PROGRAMME FOR PEOPLE WITH INFLAMMATORY ARTHRITIS}

J. Skeates $^{1}$, J. Pearson ${ }^{2}$, S. Derham ${ }^{1}$, S. Palmer ${ }^{2} .{ }^{1}$ RNHRD, Royal United Hospitals NHS Foundation Trust, Bath, United Kingdom; ${ }^{2}$ University of West England, Bristol, United Kingdom

Background: Inflammatory Arthritis [IA] adversely affects well-being, function, fatigue and strength ${ }^{1}$. Guidelines recommend people with IA should exercise to improve strength and cardiovascular fitness ${ }^{2}$. In 2015, our team introduced an evidence-based Progressive Resistance Training Programme [PRTP] for IA ${ }^{3}$.

Objectives: To evaluate the effectiveness of a PRTP within a United Kingdom National Health Service setting.

Methods: A pre- to post-treatment evaluation was conducted. People with IA attending Rheumatology Physiotherapy were offered a supervised PRTP ( 1 hour $\times 10$ weeks): 7 exercises at 70-80\% 1-repetition maximum ( $3 \times 8-12$ repetitions). Treatment outcomes included Health Assessment Questionnaire [HAQ], EQ5D-5L, 30s sit-to-stand [STS], Self-Efficacy (SARAH Trial) [SE], Grip Strength and FACIT-Fatigue [FACIT-F]. Changes in outcomes were analysed using Paired Samples t-tests and standardised mean difference (SMD).

Results: 201 patients commenced the programme between May 2015 and April 2019, with 121 participants providing complete pre-post HAQ data. Diagnoses included Rheumatoid Arthritis $(n=149)$, Psoriatic Arthritis $(n=42)$, Juvenile Idiopathic Arthritis $(n=5)$, Enteropathic IA ( $n=2)$, Oligoarthritis $(n=1)$, Reactive Arthritis $(n=1)$ and Undifferentiated IA $(n=1)$. Age $($ mean $\pm S D)=56.8 \pm 14.8$ years; number of sessions attended $=7.7 \pm 3.4$.

There were no differences between those recorded as not completing the PTRP $(n=54 ; 72 \%$ women; age $55.0 \pm 14.6$ years; HAQ $0.99 \pm 0.70$ ) versus the others $(n=147 ; 78 \%$ women; age $57.5 \pm 14.8 ; \mathrm{HAQ} 0.86 \pm 0.65)$. A pragmatic decision was made to analyse all available data for each outcome.

Table 1. Analysis of PRTP outcomes * Indicates clinical improvement.

\begin{tabular}{|c|c|c|c|c|c|}
\hline Outcome measure & $\begin{array}{l}\text { Pre- } \\
\text { treatment }\end{array}$ & $\begin{array}{l}\text { Post- } \\
\text { treatment }\end{array}$ & $\begin{array}{c}\text { Mean } \\
\text { difference } \\
(95 \% \mathrm{Cl})\end{array}$ & p-value & $\begin{array}{c}\text { Standardised } \\
\text { mean difference } \\
(95 \% \mathrm{Cl})\end{array}$ \\
\hline $\begin{array}{l}\text { HAQ } \\
\max \text { score } 3(n=121)\end{array}$ & $0.83 \pm 0.65$ & $0.70 \pm 0.67$ & $\begin{array}{c}-0.13 \\
(-0.07,-0.19)\end{array}$ & $p<0.001$ & $\begin{array}{c}-0.20^{*} \\
(-0.46,0.07)\end{array}$ \\
\hline $\begin{array}{l}\text { EQ5D VAS } \\
\text { max score } 100(n=119)\end{array}$ & $70.0 \pm 16.3$ & $76.7 \pm 15.2$ & $\begin{array}{c}6.7 \\
(9.4,3.9)\end{array}$ & $p<0.001$ & $\begin{array}{c}0.42^{*} \\
(0.17,0.68)\end{array}$ \\
\hline $\begin{array}{l}\text { STS } \\
\text { number in } 30 \text { s }(n=118)\end{array}$ & $13.2 \pm 4.9$ & $16.2 \pm 5.3$ & $\begin{array}{c}3.0 \\
(3.6,2.5)\end{array}$ & $p<0.001$ & $\begin{array}{c}0.59^{*} \\
(0.33,0.85)\end{array}$ \\
\hline $\begin{array}{l}\text { SE } \\
\max \text { score } 70(n=117)\end{array}$ & $52.3 \pm 10.4$ & $58.6 \pm 8.0$ & $\begin{array}{c}6.3 \\
(8.3,4.4)\end{array}$ & $p<0.001$ & $\begin{array}{c}0.68^{*} \\
(0.41,0.94)\end{array}$ \\
\hline $\begin{array}{l}\text { Grip Strength kg force } \\
(n=62)\end{array}$ & $20.3 \pm 9.4$ & $23.6 \pm 10.6$ & $\begin{array}{c}3.3 \\
(4.8,1.7)\end{array}$ & $p<0.001$ & $\begin{array}{c}0.33^{*} \\
(-0.03,0.68)\end{array}$ \\
\hline $\begin{array}{l}\text { FACIT-F } \\
\max \text { score } 52 \\
(n=58)\end{array}$ & $30.9 \pm 11.5$ & $35.5 \pm 12.0$ & $\begin{array}{c}4.6 \\
(7.2,2.1)\end{array}$ & $\mathrm{p}=0.001$ & $\begin{array}{c}0.39^{*} \\
(0.02,0.76)\end{array}$ \\
\hline
\end{tabular}

Conclusion: All outcome measures demonstrated statistically significant improvements. Notably, minimal clinically important differences were achieved in STS and FACIT-F. STS correlates to lower limb power, balance and endurance, and is a predictor of falls ${ }^{4}$. Fatigue significantly impacts function in people with $I \mathrm{~A}^{5}$, often limiting confidence and willingness to participate in exercise activities ${ }^{6}$.

Effective evidence-based PRTPs for people with IAs can be delivered by Physiotherapists. Improvements in function, wellbeing, self-efficacy, strength and fatigue are achievable, however, exploration of the clinical relevance of these observed changes is recommended. Further research exploring patients' perspectives of the PRTP and adherence to long-term exercise is needed. 